\title{
Effect of the milk heat treatment on properties of low-fat yogurt manufactured with microbial transglutaminase
}

\author{
Belén García-Gómez¹, Mª Lourdes Vázquez-Odériz', Nieves Muñoz-Ferreiro², \\ $M^{\text {a }}$ Ángeles Romero-Rodríguez ${ }^{1}$, Manuel Vázquez ${ }^{1 *}$ \\ ${ }^{1}$ Department of Analytical Chemistry, Faculty of Science, University of Santiago de Compostela, 27002 Lugo, Spain, ${ }^{2}$ Modestya Research \\ Group, Department of Statistics, Mathematical Analysis and Optimization, University of Santiago de Compostela, 27002 Lugo, Spain
}

\section{A B S T R A C T}

\begin{abstract}
The effect of milk heat treatment (UHT vs HTST) on physicochemical properties of low-fat set-style yogurt manufactured with microbial transglutaminase was evaluated. It was also evaluated the sensory profile of microbial transglutaminase yogurt and conventional fortified yogurt using skim milk powder. The UHT treatment of milk to make yogurts treated with microbial transglutaminase showed poorer texture results (firmness, consistency, cohesiveness and index of viscosity) than the HTST treatment of milk. Yogurt texture of UHT treatment was also worse than low-fat commercial yogurts, despite of the positive effect of the microbial transglutaminase. The microbial transglutaminase addition avoided the syneresis, regardless of the type of heat treatment. A microbial transglutaminase doses at low levels $\left(0.76 \mathrm{U} \cdot \mathrm{g}^{-1}\right.$ of milk protein) added simultaneously with the starter culture was useful for improving the textural properties and sensory characteristics of low-fat yogurt, avoiding the normal syneresis of low-fat yogurt and without increasing the protein content that happen with the addition of skim milk powder. Yogurts made with microbial transglutaminase with HTST treatment showed significantly lower whey odor than yogurt fortified with skimmed milk powder. The application of microbial transglutaminase is a useful treatment for improving textural properties of low-fat yogurt with the usual pasteurization treatment applied in the dairy industry.
\end{abstract}

Keywords: Microbial transglutaminase; Yogurt; UHT; Pasteurized; Texture; Sensory; Milk fortification

\section{INTRODUCTION}

Yogurt plays a key role in healthy nutrition since it is a good source of proteins, minerals (calcium, potassium and phosphorus) and vitamins. The nutritional value of yogurt and the importance as nutrient provider for bone health and microflora benefits and other health's benefits are well recognized (Kok and Hutkins, 2018).

Lactic acid bacteria are able to ferment and transform different raw materials into products widely consumed for their sensory and nutritional properties, such as yogurt and bread. In addition, lactic acid bacteria present in yogurt also provide healthy bioactive compounds with antioxidant properties and act as probiotics (Zhang et al., 2011). The positive effect of lactic acid bacteria is also observed in bread made with sourdought in which Sidari et al. (2020) found that lactic acid bacteria is associated with the presence of phenolic compounds with antioxidant activity.
Thus, yogurt is considered a food that must be part of a balanced diet throughout all stages of life. Although it is recommended to promote the consumption of low-fat yogurt as a healthier snack or dessert, to supply nutrients without increasing caloric intake (Williams et al., 2015). In this sense, many consumers demand less caloric yogurts but maintaining the sensory and health quality (Torrico et al., 2020). In addition, yogurt is a product that can be enriched with compounds such as microalgae with functional properties that further improve its nutritional properties and positive effects on health, such as its potential as antiinflammatory, antioxidant effect, the reinforcement of the immune system and the benefits on the cardiovascular system, on atherosclerosis and on hypertension (Sidari and Tofalo, 2019).

Protein and fat play a decisive role in the textural properties of yogurt. Therefore, the reduction of fat content in skimmed yogurts leads to associated texture defects and the presence of free whey (Lee \& Lucey, 2006; Lee \& Lucey,

\footnotetext{
${ }^{*}$ Corresponding author:

Manuel Vázquez, Department of Analytical Chemistry, Faculty of Science, University of Santiago de Compostela, 27002 Lugo, Spain.

E-mail: manuel.vazquez@usc.es
}

Received: 01 August 2020; $\quad$ Accepted: 11 October 2020 
2010; Dabija and Oroian, 2020). Traditionally, this problem is solved with the addition of different milk products such as non-fat dry milk, milk protein concentrate or whey protein concentrate (Nguyen et al., 2017) which can have negative effects on sensory properties (Pakseresht et al., 2017; Lesme et al., 2020). Moreover, the economic cost is increased for the use of these compounds (Tamine and Robinson, 1999).

Transglutaminase is an enzyme capable of catalyzing acyl transfer reactions between $\gamma$-carboxyamide groups of glutamine residues in a peptide chain of a protein and a primary amine, through different reactions: introducing covalent cross-linking between proteins, peptides and primary amines, deamination of glutamine residues and amine incorporation (Gaspar and De Góes-Favoni, 2015).

In a food matrix, the formation of covalent cross-linking $\varepsilon$-( $\gamma$-glutamyl)-lysine (G-L bonds) between proteins is the main reaction (Fatima and Khare, 2018). Consequently, the protein network structure is affected, improving physical properties such as water retention capacity and gel strength (Miwa, 2020). Its addition in food products improves the texture, flavour and rheological properties of foods. In some cases, it enhances the consumers health (Amirdivani et al., 2018). Furthermore, this enzyme is generally recognized as safe (GRAS) (Liang et al., 2020). It can be simply deactivated when the reaction has been completed by heat or $\mathrm{pH}$ (Amirdivani et al., 2018).

Microbial transglutaminase is widely used in different sectors of the food industry (Mostafa, 2020) because it has a low substrate specificity (Miwa, 2020). This enzyme was successfully applied in dairy products (Romeih and Walker, 2017), meat (Santhi et al., 2017), fish (Chen et al., 2019), bakery products (Amante et al., 2019), vegetable proteins (Xing et al., 2020), and even in edible films (Cruz-Díaz et al., 2019).

Milk proteins, mainly caseins, are an excellent substrate for microbial transglutaminase (Jaros et al., 2006). Thus, microbial transglutaminase is capable of improving the textural characteristics of different milk products (Gharibzahedi et al., 2018) like set-style yogurt (Pakseresht et al., 2017; Shi et al, 2017; Ziarno and Zaręba, 2020). The polymers formed by the microbial transglutaminase have a similar effect in functional properties than fat (Danesh et al., 2017).Therefore, the incorporation of microbial transglutaminase was proposed as a promising alternative to protein fortification in the production of skimmed yogurt, both due to the characteristics and acceptance of the final product (García-Gómez, et al., 2019a, b), as well as it is cheaper than protein fortification (Loveday et al.,
2013), solving the problems associated with the reduction of fat content (Pakseresht et al., 2017).

Microbial transglutaminase can be implemented in the yogurt production process through 2 ways: i) addition prior to fermentation: the enzyme is incorporated into the milk before adding the starter culture, subsequently the enzyme is thermally inactivated, ii) simultaneous addition with the starter culture: the starter culture and the enzyme are added at the same time, subsequently the enzyme is inactivated by $\mathrm{pH}$ decrease (Setiadi and Ramdhani, 2018).

The first procedure has the advantage that polymerization takes place at a constant $\mathrm{pH}$, although it has the disadvantage that the production process requires longer times, due to pre-incubation with the enzyme and its subsequent thermal inactivation with the associated economic costs (Bönisch et al., 2007). On the other hand, in the simultaneous addition method, the inactivation of enzyme is gradual, as the $\mathrm{pH}$ falls during fermentation. Some authors suggest that the degree of polymerization with the simultaneous adding may be lower and some residual enzyme activity may be maintained, although it seems unlikely since the $\mathrm{pH}$ drop from 6.8 to 4.2-4.6 soon after fermentation starts (Guyot and Kulozik, 2011) and the optimum $\mathrm{pH}$ range for the enzyme is around 6-7 (Ando et al., 1989). The advantage of this method of addition is that it does not require additional steps, integrating the addition of the enzyme into the standard production process (Bönisch et al, 2007).

Some authors suggest a third approach, which consists of treating the protein supplement separately using the enzyme in an aqueous solution, next drying the preparation for future use in yogurt production (Guyot and Kulozik, 2011). It is not useful when the objective of adding microbial transglutaminase is to avoid such fortification or supplementation.

Although the nutritional importance of milk and dairy products is indisputable, it is necessary to ensure the microbiological quality of milk and extend its shelf life, both for direct consumption and for the production of dairy products. The main methods used are: low temperature-long time (LTLT) pasteurization (63$65^{\circ} \mathrm{C}, 30 \mathrm{~min}$ ), high temperature-short time (HTST) pasteurization $\left(72-75^{\circ} \mathrm{C}, 10-15 \mathrm{~s}\right)$, ultrahigh pasteurization (UP) $\left(115-121^{\circ} \mathrm{C}, 2-4 \mathrm{~s}\right)$, ultrahigh temperature (UHT) sterilization $\left(135-150^{\circ} \mathrm{C}, 2-4\right.$ s) (Xing et al., 2020). The heat treatment has an important effect on the microstructure and therefore on the texture and rheology of yogurt (Sodini et al., 2004) Furthermore, it must be taken into account that the effect of microbial transglutaminase addition on the characteristics of the yogurt is different depending on the heat treatment 
applied to the milk. In general, raw milk proteins are less reactive to transglutaminase than pasteurized or UHT milk proteins. Furthermore, in raw milk there is a natural inhibitor of microbial transglutaminase that is inactivated at pasteurization temperatures (Jaros et al., 2006). Regarding the differences between the reactivity of milk proteins and microbial transglutaminase as a function of heat treatment, previous studies suggest that with pasteurization better results can be obtained although it cannot be confirmed since they were not made with the same milk or in the same conditions. These results show that both the firmness and consistency of yogurts made with microbial transglutaminase is higher in yogurts made in the pilot plant and the pasteurization is used as a heat treatment (García-Gómez et al., 2020) than yogurts made from UHT milk in the laboratory, even the enzyme dose of TG is higher (García-Gómez et al., 2018).

The aim of this work was study the effect of different milk heat treatments (UHT vs HTST) on low-fat set-style yogurt treated with microbial transglutaminase added simultaneously with the starter culture. Inoculation of the microbial transglutaminase was simultaneously with the inoculation of the starter culture, since this via no require additional processing time, heat treatment or additional equipment (Bönisch et al., 2007). For achieved the main objective, in a first step, physicochemical properties were measured. Commercial low-fat and full-fat yogurts were included in the study for comparative purposes. Then, in a second step, yogurts made by applying the selected milk heat treatment combined with the addition of the enzyme was compared from a sensorial point of view with a control yogurt, fortified with skimmed milk powder, which is the usual procedure used in the industry for the production of skim yogurt. Commercial low-fat yogurts were included in the study for comparative purposes.

\section{MATERIALS AND METHODS}

\section{Raw materials}

Skimmed milk (fat, $0.02 \%$; protein, $3.10 \%$, total dry matter, $9.35 \%$ ) was used for yogurt manufacture. Commercial skimmed milk powder was used for conventional yogurt fortification as control. Microbial transglutaminase (TG) was obtained in our laboratory following the manufacture process described in our Spanish patent ES-2376439 (Vázquez and Guerra-Rodríguez, 2012).

\section{Yogurt manufacture}

For physicochemical measurements, two batches using HTST milk (batch A) and UHT milk (batch B) were produced and compared with commercial yogurts (Fig. 1). Batches were heated at the incubation temperature $\left(43^{\circ} \mathrm{C}\right)$.
Freeze-dried lactic culture (LyoCulture Dairy, BDF Natural Ingredients, Girona, Spain) at $0.20 \mathrm{~g} \cdot \mathrm{L}^{-1}$ of milk was inoculated and blended into the milk. The enzyme dosage used for the batches was $0.76 \mathrm{U} \cdot \mathrm{g}^{-1}$ of milk protein.

Once the best heat treatment of milk was selected, two different batches were made for sensory evaluation (Figure 1). The yogurts with microbial transglutaminase were elaborated according to the procedure described above (batch $\mathrm{C}$ ), although in the yogurt considered as control, the milk was fortified with skimmed milk powder (SMP) until reaching a protein content of $38.0 \%$ and microbial transglutaminase was not added (batch D).

The mixture was poured into $125 \mathrm{~g}$ plastic cups and incubated at $43^{\circ} \mathrm{C}$. Yogurts were stored at $4^{\circ} \mathrm{C}$ until they were analyzed. All yogurts, except commercial ones, were made on a laboratory scale.

\section{Texture profile analysis}

The parameters of instrumental texture were measured using a TA-XTplus texturometer (Stable Micro System, Viena Court, UK). A back-extrusion rig (model A/BE, $40 \mathrm{~mm}$ inner diameter) with a cylindrical probe of 35 $\mathrm{mm}$ diameter was used. The instrument was adjusted to a penetration speed of $60 \mathrm{~mm} / \mathrm{s}$ and a penetration distance of $80 \%$ of initial height (Fig. 2). Five samples of $125 \mathrm{~g}$ were measured at $15^{\circ} \mathrm{C}$. Four parameters were measured: (i) firmness ( $\mathrm{g}$ ), was defined as the peak of the maximum force; (ii) consistency (g s), was taken as the area of the curve up to the point of firmness; (iii) cohesiveness (g), was defined as the maximum negative force during the returning of the probe and (iv) index of viscosity ( $g \mathrm{~s}$ ), was defined as the total negative area obtained when the probe returns.

\section{Other instrumental analysis}

Initial syneresis (syneresis.i) was determined as the liquid released on the surface of yogurt weighed (Farnsworth et al., 2006). Six replicates were analyzed for each batch. Residual syneresis (syneresis.r) was determined as the liquid released in a sample with $30 \mathrm{~g}$ of yogurt prepared in centrifuge cups and centrifuged at $222 \mathrm{~g}$ and $10^{\circ} \mathrm{C}$ for $10 \mathrm{~min}$ (Tamjidi et al., 2012). The clear supernatant was collected and weighed. Four replicates were analyzed for each batch.

Water activity (Aw) was measured using an AquaLab meter equipment (Meter Food, Pullman, USA). Three replicates were analyzed for each batch. The $\mathrm{pH}$ was determined using a portable pH meter (PCE-PH22, PCE Holding GmbH, Meschede, Germany).

\section{Sensory analysis}

The samples were evaluated by a trained panel performed by 15 trained judges with previous experience ( 10 women and 5 men) with a mean age of 46.8 years (García-Gómez 
A

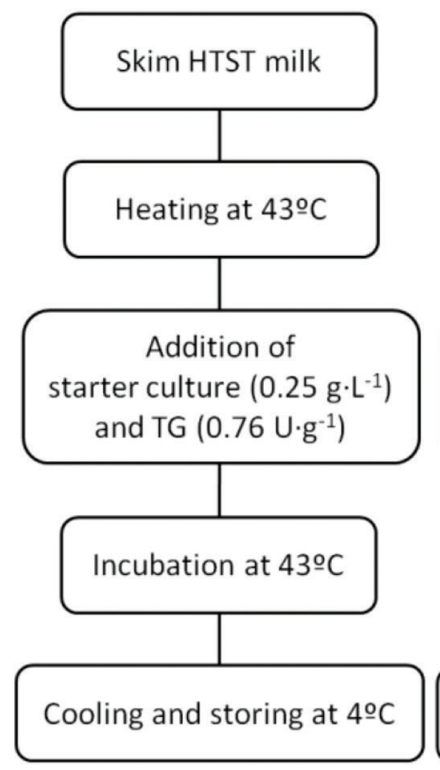

B

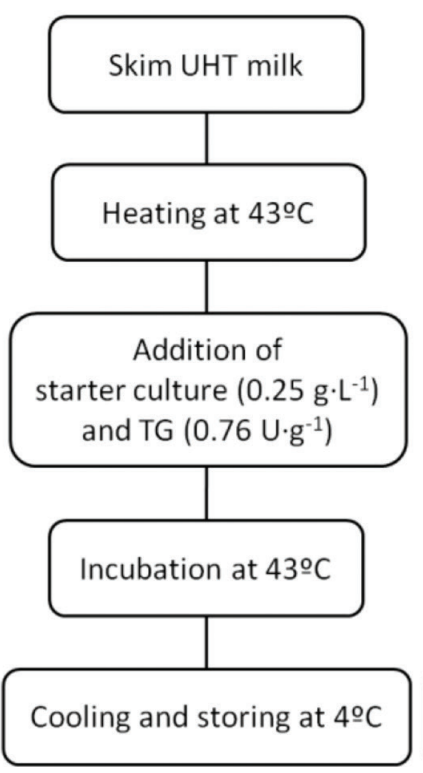

C

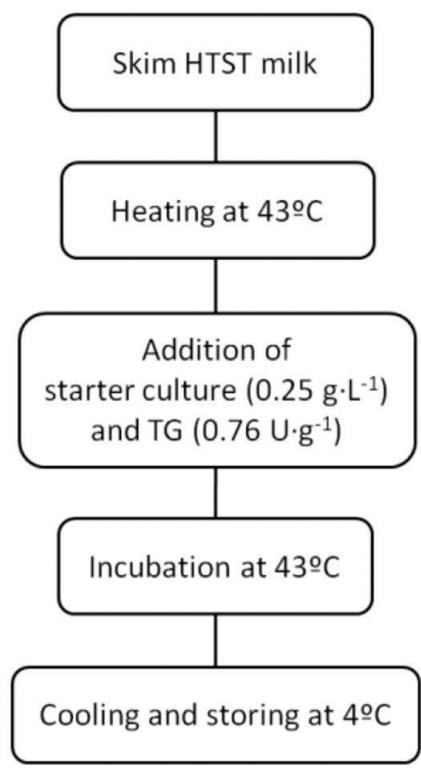

D

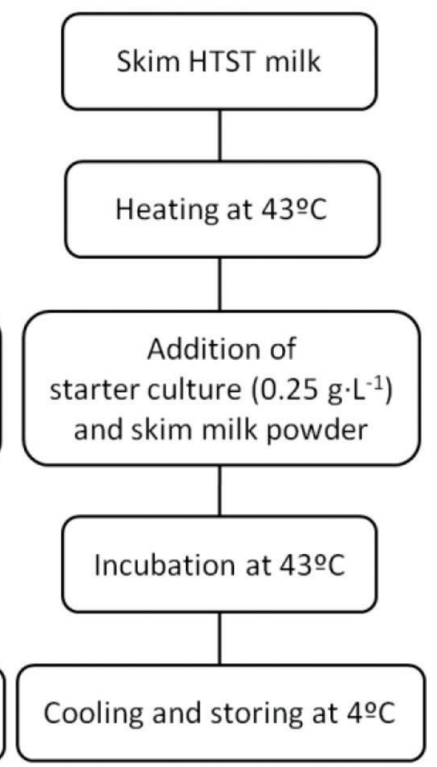

Fig 1. Manufacture of set yogurt samples. A (yogurt manufactured with skim HTST milk and microbial transglutaminase) and B (yogurt manufactured with skim UHT milk and microbial transglutaminase): batches for physicochemical measurements; C (yogurt manufactured with skim HTST milk and microbial transglutaminase) and D (yogurt manufactured with skim HTST milk and fortified with skim milk power): batches for sensory measurements.

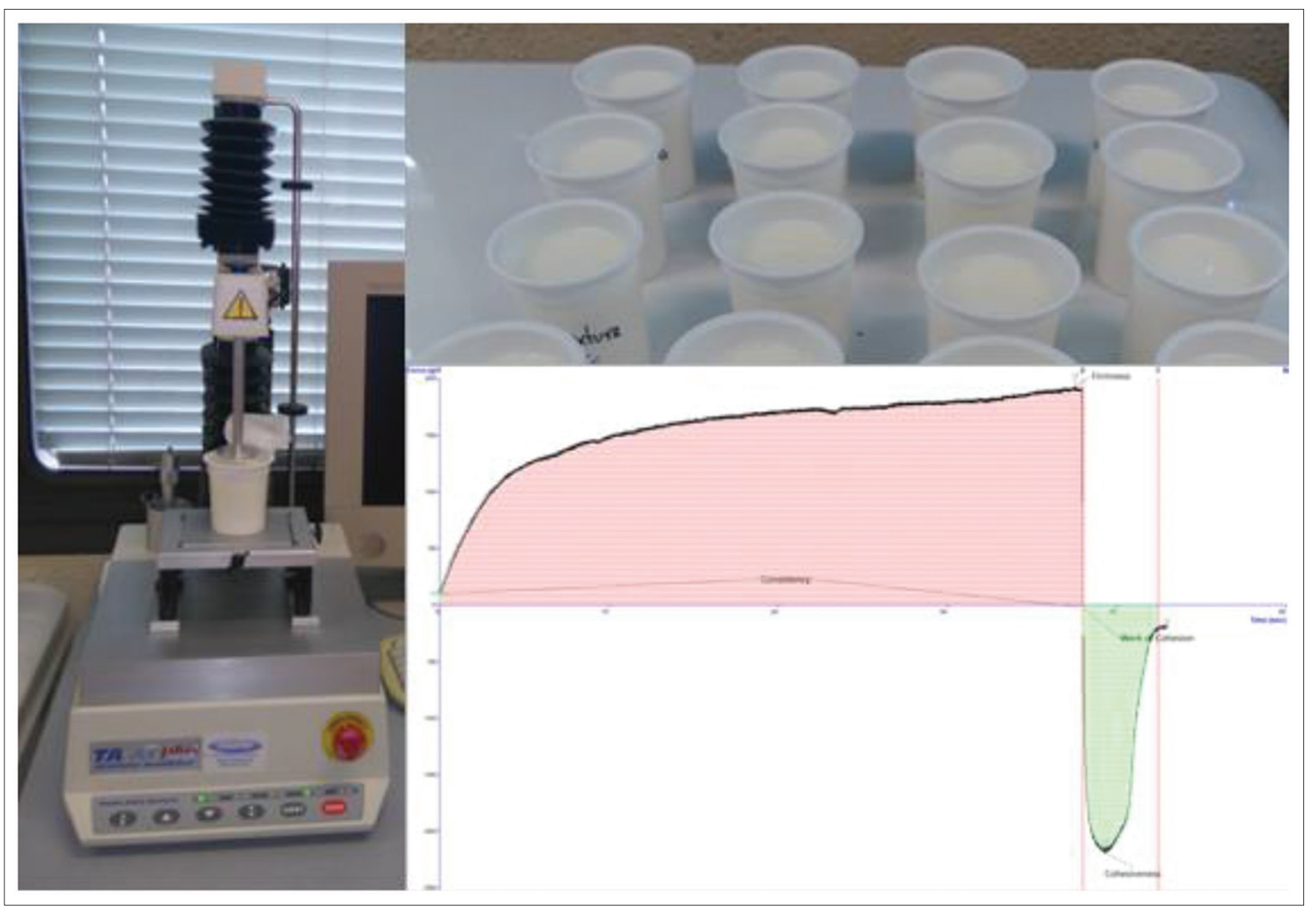

Fig 2. Performance of instrumental texture profile analysis and an example of result. 
Table 1: Definition and evaluation procedure for the sensory descriptors

\begin{tabular}{|c|c|c|c|}
\hline Descriptor & Definition & Scale and references & \\
\hline Whey odor & $\begin{array}{l}\text { Odor perceived when holding the yogurt close to the nose } \\
\text { caused by the whey produced in the yogurt process }\end{array}$ & $0=$ Diluted yogurt whey $(1: 4)$ & $10=$ Yogurt whey \\
\hline Firmness & Force required to lift the product with a coffee spoon & $0=$ Custard & $10=$ Vanilla flan \\
\hline Density & $\begin{array}{l}\text { Perception of compactness and body after introducing } \\
\text { the sample in the mouth and compressed it between the } \\
\text { tongue and the palate }\end{array}$ & $0=$ Curd & 10=Petit Suisse \\
\hline Creaminess & $\begin{array}{l}\text { Perception of thickness and smoothness pressing the } \\
\text { sample between the tongue and palate }\end{array}$ & $0=$ Curd & 10=Mayonnaise \\
\hline Acid taste & $\begin{array}{l}\text { Basic taste similar to that produced by dilute aqueous } \\
\text { solutions of citric acid }\end{array}$ & $0=0.13 \mathrm{~g} / \mathrm{L}$ citric acid solutions & $10=0.60 \mathrm{~g} / \mathrm{L}$ citric acid solutions \\
\hline Bitter taste & $\begin{array}{l}\text { Basic taste similar to that produced by dilute aqueous } \\
\text { solutions of caffeine }\end{array}$ & $0=0.03 \mathrm{~g} / \mathrm{L}$ caffeine solutions & $10=0.17 \mathrm{~g} / \mathrm{L}$ caffeine solutions \\
\hline Astringency & $\begin{array}{l}\text { Shrinking or drying effect on the mouth surface caused by } \\
\text { produced by dilute aqueous solutions of tannic acid }\end{array}$ & $0=$ Not detected & $10=0.1 \mathrm{~g} / \mathrm{L}$ tannic acid solutions \\
\hline Persistency & $\begin{array}{l}\text { Time of persistence of the olfactory/gustatory sensation } \\
\text { perceived after the bolus has been swallowed or ejected }\end{array}$ & $0=<20 \mathrm{~s}$ & $10=>60 \mathrm{~s}$ \\
\hline
\end{tabular}

et al., 2019c). Judges evaluated the intensity of quantitative sensory descriptors for each sample (ISO, 2012) using an unstructured $10-\mathrm{cm}$-line scale anchored with appropriate references (Table 1).

The assessments were carried out at a standard sensory laboratory room equipped with isolated taste booths (ISO, 2007). Each sample was labelled with random 3-digit codes, and the evaluations were performed in accordance with a randomised complete block experimental design. The samples were presented to the judges in $125 \mathrm{~g}$ plastic cups at $8{ }^{\circ} \mathrm{C}$. Tap water and crackers were available to clean palate.

\section{Statistical analysis}

Due to the assumptions required for parametric tests (normality and homoscedasticity) were not met, the non-parametric Kruskal-Wallis test was performed in order to study differences between yogurt samples in physicochemical parameters. Nonparametric analog to Fisher's LSD for rank sums test was applied to study significant pairwise differences (García et al., 2016). Comparisons on sensory data were made using the non-parametric Wilcoxon's paired signed-ranks test (Bower, 2009). Statistical analyzes were performed with the $\mathrm{R}$ language ( $\mathrm{R}$ Core Team, 2019). The agricolae (De Mendiburu, 2017) R. package was used.

\section{RESULTS AND DISCUSSION}

\section{Texture and physical analysis of TG yogurts}

Fig. 3 shows the texture results for the yogurt manufactured with HTST skim milk (a) and the yogurt manufactured with UHT skim milk (b), both using microbial transglutaminase. For comparative purpose, the texture results of commercial low and full-fat yogurts were included.
Yogurt made from pasteurized milk and microbial transglutaminase (HTST+TG) has been found to be significantly firmer (432.21 g) than that made from UHT milk and microbial transglutaminase (UHT+TG) $(125.22 \mathrm{~g})$ (p-value<0.001). It was also firmer that any of the commercial low or full-fat yogurts ( $\mathrm{p}$-value $<0.001$ and $\mathrm{p}$-value $<0.01$, respectively). The observed trend for consistency was similar, since the HTST+TG sample showed a significantly ( $\mathrm{p}$-value $<0.001)$ higher consistency (9405.66 $\mathrm{g} \cdot \mathrm{s})$ than the UHT+TG sample (2929.17 g•s). The HTST+TG sample was also more consistent than commercial low-fat samples ( $\mathrm{p}$-value $<0.05)$ and commercial full-fat ( $\mathrm{p}$-value $<0.001)$. Regarding cohesiveness and viscosity index, the HTST+TG yogurt obtained significantly higher values than the UHT+TG ( $p$-value $<0.001)$ and similar values than the commercial ones.

Literature in this field has also observed a significant increase in gel strength when adding TG to full-fat yogurts at the same time as the starter culture at doses around 0.8 $\mathrm{U} \cdot \mathrm{g}^{-1}$ comparing them both with an enzyme-free control and with a fortified with milk protein yogurts (Mahmood and Sebo, 2012). Taking into account that commercial yogurts were made from pasteurized milk, a standard procedure in the dairy industry (Lucey, 2004), the lower firmness of yogurt made with UHT milk (although TG was added) is due to the fact that severe heat treatments such as UHT leads to a negative effect on yogurt texture. Both the firmness and viscosity values observed in yogurts made with UHT milk were lower than those observed in yogurts made with milk subjected to less intense heat treatments (Sodini et al., 2004). Similar results were shown by others who observed that a yogurt made with pasteurized milk had greater firmness and viscosity than that made with UHT milk (Schmidt et al., 1985). 


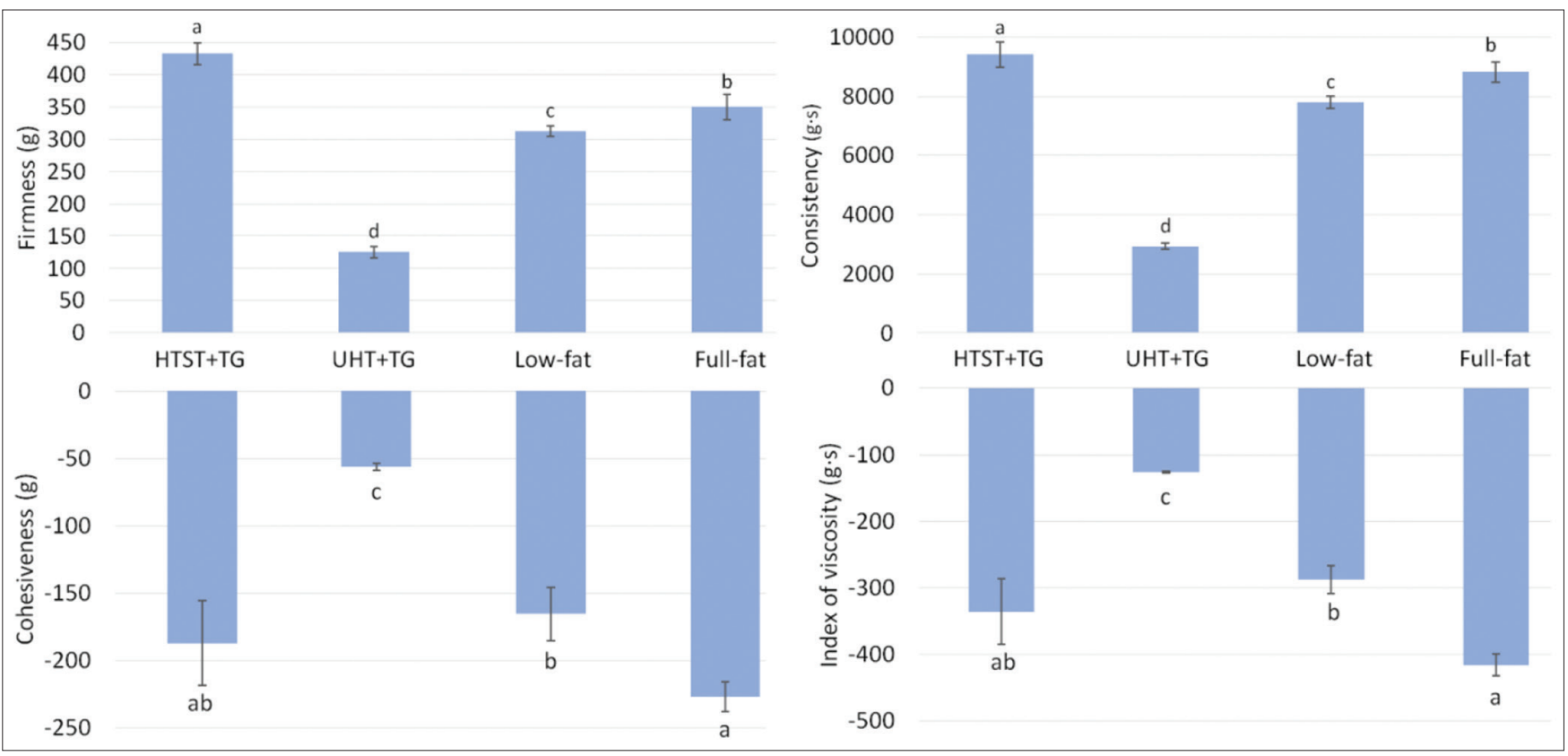

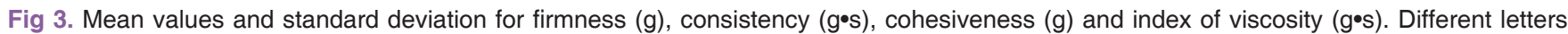
show significative statistical differences between yogurt samples. HTST+TG was made with High Temperature Short Time treated (pasteurized) skim milk and microbial transglutaminase, UHT+TG was made with Ultra High Temperature treated skim milk and microbial transglutaminase, Low-fat is a commercial low-fat yogurt and Full-fat is a commercial full-fat yogurt).

On the other hand, previous investigations observed a low reactivity of microbial transglutaminase in unheated or pasteurized milk (Şanli et al., 2011), despite the fact that caseins are a good substrate for microbial transglutaminase (Jaros et al., 2006). This fact was attributed to the presence of a natural inhibitor of microbial transglutaminase present in raw cow, goat and sheep milk. The inhibitor was estimated to be present in concentrations around $1.5 \mathrm{mg} \cdot \mathrm{L}^{-1}$ and the mechanism of inhibition is believed to be related to the binding of this inhibitor to the active center of cysteine, blocking it and avoiding the polymerization. When the concentration of microbial transglutaminase is very high, the amount of inhibitor would not be able to block all the active sites, and a certain degree of polymerization could be observed (Dejong et al., 2003). The inhibitor could be inactivated by heat treatment (Bönisch et al., 2006). Thus, the application of a heat treatment is required, prior to the addition of the enzyme (71-92 ${ }^{\circ} \mathrm{C} / 15 \mathrm{~s}-75 \mathrm{~min}$ ) (Lorenzen, et al., 2002; Özer, et al., 2007; Bönisch et al., 2007; Iličić et al., 2008; Iličić et al., 2014). The effect of the inhibitor can also be neutralized by chemical blocking, adding the reducing agent glutathione, in fact some commercial microbial transglutaminase formulations already incorporate glutathione in their formulation in order to improving the enzymatic cross-linking in unheated or pasteurized milk for yogurt production without the need to use very high concentrations of microbial transglutaminase (Bönisch et al., 2007).

However, our results confirmed that a HTST treatment of milk is sufficient to inactivate the inhibitor, since the
TG concentration used is low and an adequate degree of polymerization is reached based on the texture parameters obtained compared to the commercial samples analyzed. Our results are in agreement with previously research where it concluded that the proteins in skimmed milk were susceptible to being bound by microbial transglutaminase, with the majority of milk proteins, $\kappa$-caseins, being the most reactive followed by $\alpha$-lactalbumin although, a heat treatment equivalent to pasteurization increased the reactivity of k-caseins and $\beta$-lactoglobulins (Sharma et al., 2001).

The UHT treatment was associated with an opening of the structure of casein micelles (Bönisch et al., 2004) and with the denaturation of $\beta$-lactoglobulin (O'Sullivan et al., 2002), improving the accessibility of TG and, therefore both improving the degree of polymerization, although the thermal inactivation of the TG inhibitor seemed to be the dominant effect that explains the better crosslinking of casein micelles treated with UHT (Bönisch et al., 2004).

The viscosity of a yogurt made from pasteurized skim milk and treated with transglutaminase, added at the same time as the starter culture, was higher than that obtained for an untreated control yogurt (Özer et al., 2007). Similar results were observed in a full-fat yogurt (Şanli et al., 2011) and in whole goat milk yogurts (Domagała, et al., 2013). Other authors obtained lower values in adhesiveness and cohesiveness than those obtained in the present study in yogurts made with pasteurized milk $3.00 \%$ protein content) treated with an enzyme formulation containing 
glutathione, previously added to the starter and using a higher transglutaminase dose $\left(2.2 \mathrm{U} \cdot \mathrm{g}^{-1}\right)$ than that used in the present study $\left(0.76 \mathrm{U} \cdot \mathrm{g}^{-1}\right)$ (Tsevdou et al., 2013). It was again confirmed that the pasteurization treatment is sufficient to inactivate the inhibitor without the need for glutathione addition to obtain a yogurt with good textural properties, since in the present study the formulation does not contain glutathione nor were adding high doses of enzyme.

It was not necessary to use more intense heat treatments such as UHT (Bönisch et al., 2006), which can even have negative effects on the formation of the gel network as we observed in the present study. Therefore, the addition of transglutaminase in the production of yogurts allows obtaining firmer skimmed yogurts, even than full-fat commercial ones, without adding any type of fortification. This results coincided with those obtained in previously studies (Lucey, 2004; Yüksel and Erdem, 2010). The yogurts treated with microbial transglutaminase did not show syneresis (Table 2). Therefore, the results were significantly better than for commercial yogurts ( $\mathrm{p}$-value $<0.001)$. This agreed with the previous results, confirming that the addition of microbial transglutaminase prevents the undesired serum on the yogurts surface.

The microbial transglutaminase through the crosslinking creates a stable and compact microstructure with a very small pore size (Myllärinen et al., 2007; Özer et al., 2007). The whey is retained in this microstructure, decreasing or avoiding syneresis in set type yogurts (Şanli et al., 2011). These results were consistent with the significant $(\mathrm{p}$-value $<0.001)$ higher values of residual syneresis observed in yogurts treated with the microbial transglutaminase (Table 2), since when the gel was stirred to measure residual syneresis the network was destabilized, releasing the retained serum. On the other hand, the commercial full-fat yogurt showed a lesser amount of initial syneresis than the low-fat commercial one ( $p$-value $<0.001$ ), which was justified by the effect of the fat content of the milk on the microstructure of the gel network. It reduces the pore size and increases the size of the clusters, then the serum is retained (Pereira et al., 2006). Thus, it confirms that microbial transglutaminase can substitute, in terms of technical-functional properties, "the fat content" in set yogurts.

Statistically significant differences $(\mathrm{p}$-value $<0.05)$ were observed in the $\mathrm{pH}$ of the UHT+TG and HTST+TG samples (Table 2). In the first one, $\mathrm{pH}$ exceeded 4.7. From this level of $\mathrm{pH}$, the strength of the gel decreases. This fact would justify the lower firmness of this sample compared to the HTST+TG sample and the commercial ones. However, Romeih et al. (2014) did not also find significant differences in the $\mathrm{pH}$ of full-fat yogurt, low-fat yogurt and low-fat yogurt treated with microbial transglutaminase made with pasteurized buffalo milk. Other researchers did find a significant effect of the enzyme treatment on the $\mathrm{pH}$ of yogurts made with full-fat milk (adding the enzyme before or at the same time as the starter), comparing them with a control without transglutaminase and using an enzyme dose higher than our dose (Mahmood and Sebo, 2012). In yogurts made with pasteurized skimmed milk, a higher $\mathrm{pH}$ was observed in the treated samples, although they added the enzyme before the starter culture. They used higher doses than ours. The increase in $\mathrm{pH}$ was attributed to the interference of the transglutaminase in the growth of lactic acid bacteria, slowing down the development of acidity and the production of acetaldehyde, which led to a lower sensory perception of the acid taste and typical aromas of yogurt (Özer et al., 2007). The interference is due to the fact that the microbial transglutaminase cross-linked amino acids and small peptides. Therefore, they were not bioavailable for bacterial growth, although it seems that this effect was observed mainly when the transglutaminase is previously added to the starter (Lorenzen et al., 2002). On the contrary, other studies did not observe a significant effect of the addition of microbial transglutaminase, nor of the increase in the dose of the enzyme in the $\mathrm{pH}$ of yogurts made with pasteurized whole goat milk (Domagała et al., 2013). No significant differences were achieved between samples in the values of activity water (Table 2).

\section{Sensory analysis comparing TG vs SMP yogurts}

Fig. 4 shows the sensory results for the yogurt manufactured with HTST skim milk using microbial transglutaminase (c)

Table 2: Mean values and standard deviation for initial syneresis $\left(\mathbf{g} \cdot \mathbf{g}^{-1}\right), \mathrm{pH}$, aw and residual syneresis $\left(\mathbf{g} \cdot \mathrm{g}^{-1}\right)$. Different letters show significative statistical differences between yogurt samples. HTST+TG was made with High Temperature Short Time treated (pasteurized) skim milk and microbial transglutaminase, UHT+TG was made with Ultra High Temperature treated skim milk and microbial transglutaminase, Low-fat is a commercial low-fat yogurt and full-fat is a commercial full-fat yogurt

\begin{tabular}{|c|c|c|c|c|c|c|c|c|}
\hline \multirow[t]{2}{*}{ Sample } & \multicolumn{2}{|c|}{ Initial syneresis $\left(\mathbf{g} \cdot \mathbf{g}^{-1}\right)$} & \multicolumn{2}{|c|}{$\mathrm{pH}$} & \multicolumn{2}{|c|}{ aw } & \multicolumn{2}{|c|}{ Residual syneresis $\left(g^{\cdot} \cdot g^{-1}\right)$} \\
\hline & Mean & Deviation & Mean & Deviation & Mean & Deviation & Mean & Deviation \\
\hline HTST+TG & $0.0000^{c}$ & 0.0000 & $4.57^{b}$ & 0.01 & $0.991^{a}$ & 0.001 & $0.2742^{a}$ & 0.0191 \\
\hline UHT+TG & $0.0000^{c}$ & 0.0000 & $4.73^{a}$ & 0.00 & $0.992^{\mathrm{a}}$ & 0.002 & $0.2252^{b}$ & 0.0153 \\
\hline Low-fat & $0.0001^{a}$ & 0.0000 & $4.20^{c}$ & 0.00 & $0.986^{a}$ & 0.001 & $0.0854^{d}$ & 0.0180 \\
\hline Full-fat & $0.0000^{b}$ & 0.0000 & $4.21^{c}$ & 0.01 & $0.991^{\mathrm{a}}$ & 0.006 & $0.1684^{c}$ & 0.0048 \\
\hline
\end{tabular}




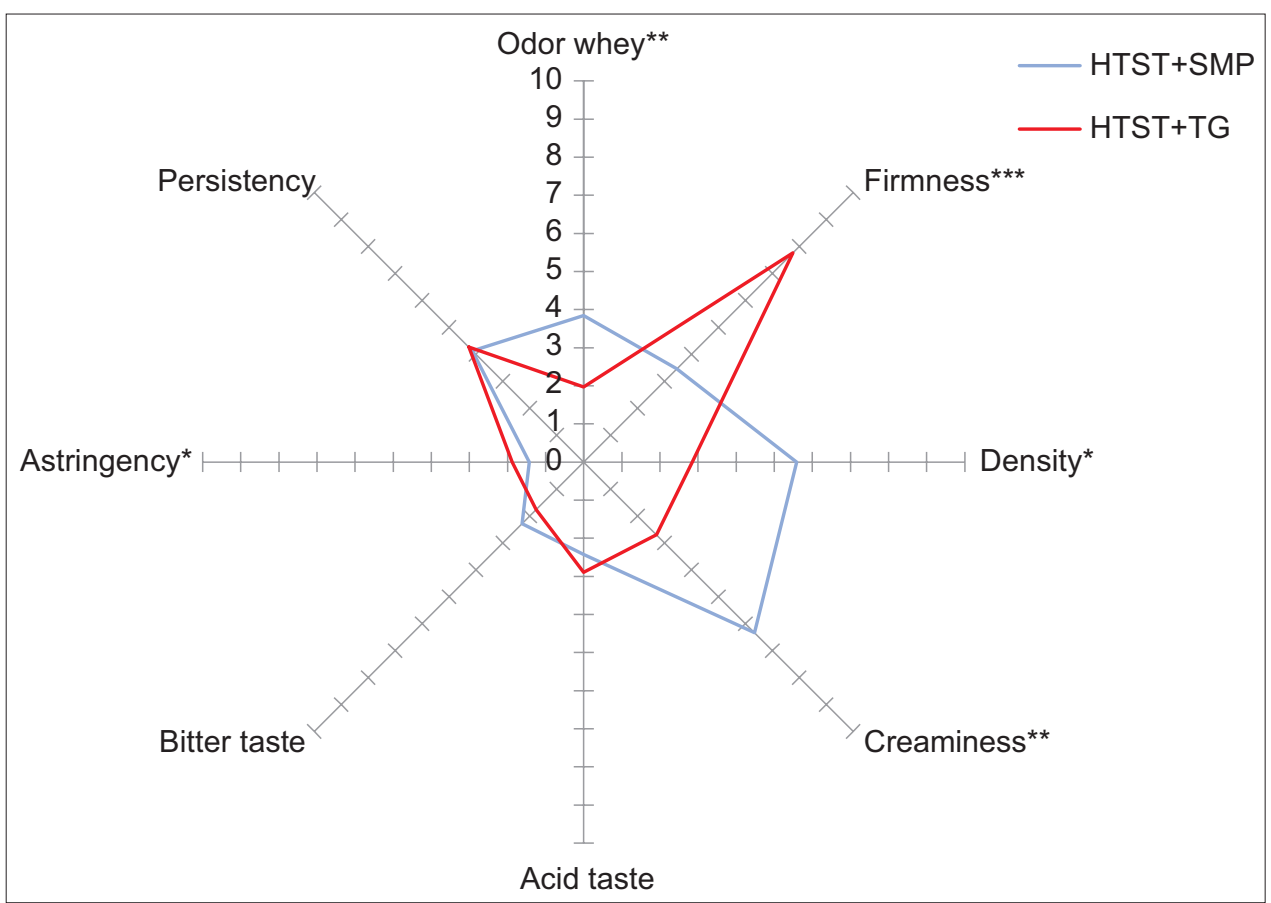

Fig 4. Sensory profile of yogurt manufactured with pasteurized milk and treated with microbial transglutaminase (HTST+TG) and a control yogurt manufactured with pasteurized milk and fortified with skim milk powder (SMP). Significant differences: ${ }^{*} p-v a l u e<0.05$, ${ }^{* *} p$-value $<0.01$ and *** p-value $<0.001$.

and yogurt manufactured with HTST milk and fortified with skim milk powder (d) instead of using microbial transglutaminase.

Yogurts made with microbial transglutaminase with HTST treatment (HTST+TG) had significantly lower whey odor ( $\mathrm{p}$-value $<0.01)$ than yogurt fortified with skimmed milk powder (HTST+SMP) $(1.97$ vs. $3.84 \mathrm{~cm})$. With the addition of transglutaminase, a significantly higher firmness $(+4.3 \mathrm{~cm})$ was obtained than with skimmed milk powder (p-value $<0.001)$. However, yogurt treated with microbial transglutaminase is less dense $(\mathrm{p}$-value $<0.05)$ and creamy (p-value $<0.01)$ than that fortified with SMP, with 2.74 and $3.64 \mathrm{~cm}$ difference between the samples, respectively. Regards basic tastes and aroma, only significant differences ( $p$-value $<0.05)$ in astringency were observed (Figure 3). In a pilot plant study, a similar comparison was proposed, a control yogurt fortified with skimmed milk powder was compared with another made with the enzyme, using the same transglutaminase, the same dose and the same enzyme addition procedure. Significant differences were also observed in whey odor, firmness, density, creaminess, and, unlike on a laboratory scale, differences in acid taste were also found (García-Gómez et al., 2019c). Another trial, with yogurts also made in a pilot plant, with the same dose and the same method of addition, although using another transglutaminase showed similar results when compared to a control yogurt (García-Gómez et al, 2019a, b).
Other investigations reached similar conclusions regarding the sensory properties of a skimmed yogurt made with pasteurized milk and treated with microbial transglutaminase, added before the starter culture.

Transglutaminase treated yogurt showed lower serum odor intensity and firmer than control yogurt, although contrary to the present study they found that transglutaminasetreated yogurts were less acid and creamy than control yogurt (Lorenzen et al., 2002). However, in a study that compared a control yogurt made from pasteurized whole milk with a yogurt made from the same milk to which they added transglutaminase at the same time as the starter culture, they did not observe differences in odor, although if differences were observed in the texture (Şanli et al., 2011). In another study they also compared a control yogurt with another treated with transglutaminase added at the same time as the starter culture, both made with pasteurized whole milk and found significant differences in texture and acid taste. (Mahmood and Sebo, 2012).

\section{CONCLUSIONS}

The UHT treatment of milk to make yogurts treated with microbial transglutaminase lead to poorer texture results than the HTST treatment. The texture obtained with UHT milk is also worse than that of commercial skimmed yogurts. 
The HTST treatment appears to be sufficient to improve the reactivity of milk proteins with microbial transglutaminase. It also inactivates the microbial transglutaminase inhibitors naturally present in the milk. Thus, there is no requirement to use transglutaminase formulations containing glutathione or to apply intense heat treatments such as UHT. Therefore, the application of microbial transglutaminase is a useful treatment for improving textural properties of low-fat yogurt with the usual pasteurization treatment applied in the dairy industry.

Regarding syneresis, good results were obtained with both HTST and UHT treatment.

The microbial transglutaminase addition simultaneously with the starter culture allows reduce the fat content and to obtain yogurts with similar physicochemical and sensory characteristics as full-fat yogurts without increasing the protein content.

\section{ACKNOWLEDGEMENT}

This research was supported by MICINN (Spain) (project RTC2014-1835-2).

\section{Author's contributions}

Belén García-Gómez: Investigation; Writing-original draft. $\mathrm{M}^{\mathrm{a}}$ Lourdes Vázquez-Odériz: Writing-review \& editing. Nieves Muñoz-Ferreiro: statistical analysis. $\mathrm{M}^{\mathrm{a}}$ Ángeles Romero-Rodríguez: Writing-review \& editing. Manuel Vázquez: Conceptualization, Funding acquisition, Writingreview \& editing.

\section{REFERENCES}

Amante, P. R., C. A. Fante and R. L. Pires. 2019. Use of transglutaminase in bakery products. J. Culin Sci. Technol. 17: $1-11$.

Amirdivani, S., N. Khorshidian, M. Fidelis, D. Granato, M. R. Koushki, M. Mohammadi, K. Khoshtinat and M. Mortazavian. 2018. Effects of transglutaminase on health properties of food products. Curr. Opin. Food Sci. 22: 74-80.

Ando, H., M. Adachi, K. Umeda, A. Matsuura, M. Nonaka, R. Uchio, H. Tanaka and M. Motoki. 1989. Purification and characteristics of a novel transglutaminase derived from microorganisms. Agric. Biol. Chem. 53: 2613-2617.

Bönisch, M. P, M. Huss, S. Lauber and U. Kulozik. 2007. Yoghurt gel formation by means of enzymatic protein cross-linking during microbial fermentation. Food Hydrocoll. 21: 585-595.

Bönisch, M. P., M. Huss, K. Weitl and U. Kulozik. 2007. Transglutaminase cross-linking of milk proteins and impact on yoghurt gel properties. Int. Dairy J. 17: 1360-1371.

Bönisch, M. P., S. Lauber and U. Kulozik. 2004. Effect of ultra-high temperature treatment on the enzymatic cross-linking of micellar casein and sodium caseinate by transglutaminase. J. Food Sci. 69: 398-404.
Bönisch, M. P., S. Lauber and U. Kulozik. 2007. Improvement of enzymatic cross-linking of casein micelles with transglutaminase by glutathione addition. Int. Dairy J. 17: 3-11.

Bönisch, M. P., A. Tolkach and U. Kulozik. 2006. Inactivation of an indigenous transglutaminase inhibitor in milk serum by means of UHT-treatment and membrane separation techniques. Int. Dairy J. 16: 669-678.

Bower, J. A. 2009. Statistical Methods for Food Science: Introductory Procedures for the Food Practitioner. $1^{\text {st }}$ ed. Wiley-Blackwell, Oxford.

Chen, C., K. Takahashi, L. Geonzon, E. Okazaki and K. Osako. 2019. Texture enhancement of salted Alaska pollock (Theragra chalcogramma) roe using microbial transglutaminase. Food Chem. 290: 196-200.

Cruz-Díaz, K., Á. Cobos, M. E. Fernández-Valle, O. Díaz and M. I. Cambero. 2019. Characterization of edible films from whey proteins treated with heat, ultrasounds and/or transglutaminase. Application in cheese slices packaging. Food Packag. Shelf Life. 22: 100397.

Dabija, A. and M. Oroian. 2020. Assesement the Influence of the Main Tecnological Factors on Yoghurt Quality. Vol. 21. St Cerc St CICBIA, pp. 83-94.

Danesh, E., M. Goudarzi and H. Jooyandeh. 2017. Short communication: Effect of whey protein addition and transglutaminase treatment on the physical and sensory properties of reduced-fat ice cream. J. Dairy Sci. Am. Dairy Sci. Assoc. 100: 5206-5211.

De Jong, G. A. H., G. Wijngaards and S. J. Koppelman. 2003. Transglutaminase inhibitor from milk. J Food Sci. 68: 820-825.

De Mendiburu, F. 2017. Agricolae: Statistical Procedures for Agricultural Research. R Package Version, No. 1.2-8

Domagała, J., M. Wszołek, A. Y. Tamime and B. Kupiec-Teahan B. 2013. The effect of transglutaminase concentration on the texture, syneresis and microstructure of set-type goat's milk yoghurt during the storage period. Small Rumin. Res. 112: 154-161.

Farnsworth, J. P., J. Li, G. M. Hendricks and M. R. Guo. 2006. Effects of transglutaminase treatment on functional properties and probiotic culture survivability of goat milk yogurt. Small Rumin. Res. 65: 113-121.

Fatima, S. W. and S. K. Khare. 2018. Current insight and futuristic vistas of microbial transglutaminase in nutraceutical industry. Microbiol. Res. 215: 7-14.

García, S., D. Molina, M. Lozano and F. Herrera. 2009. A study on the use of non-parametric tests for analyzing the evolutionary algorithms' behaviour: A case study on the CEC'2005 special session on real parameter optimization. J. Heuristics. 15: 617-644.

García-Gómez, B., Á. Romero-Rodríguez, L. Vazquez-Odériz, N. Muñoz-Ferreiro and M. Vázquez. 2018. Physicochemical evaluation of low-fat yoghurt produced with microbial transglutaminase. J. Sci. Food Agric. 98: 5479-5485.

García-Gómez, B., Á. Romero-Rodríguez, L. Vazquez-Odériz, N. Muñoz-Ferreiro and M. Vázquez. 2019a. Skim yoghurt with microbial transglutaminase: Evaluation of consumer acceptance. CYTA J. Food. 17: 280-287.

García-Gómez, B., Á. Romero-Rodríguez, L. Vazquez-Odériz, N. Muñoz-Ferreiro and M. Vázquez. 2019b. Sensory quality and consumer acceptance of skim yoghurt produced $w$ ith transglutaminase at pilot plant scale. Int. J. Dairy Technol. 72: 388-394.

García-Gómez, B., Á. Romero-Rodríguez, L. Vazquez-Odériz, N. Muñoz-Ferreiro and M. Vázquez. 2019c. Sensory evaluation of low-fat yoghurt produced with microbial transglutaminase and 
comparison with physicochemical evaluation. J. Sci. Food Agric. 99: 2088-2095.

García-Gómez, B., Á. Romero-Rodríguez, L. Vazquez-Odériz, N. Muñoz-Ferreiro and M. Vázquez. 2020. Effect of storage time on sensory and instrumental properties of skim-milk yoghurt obtained with microbial transglutaminase. Int. J. Dairy Technol. 73: 157-167.

Gaspar, A. L. C. and G. S. P. De Góes-Favoni. 2015. Action of microbial transglutaminase (MTGase) in the modification of food proteins: A review. Food Chem. 171: 315-322.

Gharibzahedi, S. M. T., M. Koubaa, F. J. Barba, R. Greiner, S. George and S. Roohinejad. 2018. Recent advances in the application of microbial transglutaminase crosslinking in cheese and ice cream products: A review. Int. J. Biol. Macromol. 107: 2364-2374.

Guyot, C. and U. Kulozik. 2011. Effect of transglutaminase-treated milk powders on the properties of skim milk yoghurt. Int. Dairy J. 21: 628-635.

Shi, J., D. Li and X. H. Zhao. 2017. Quality attributes of the set-style skimmed yoghurt containing enzymatic cross-linked or thermal polymerized whey protein isolate. CyTA J. Food. 15: 34-40.

Iličić, M. D., M. D. Carić, S. D. Milanović, L. P. Dokić, M. S. Duric, G. S. Bošnja and K. G. Duraković. 2008. Viscosity changes of probiotic yoghurt with transglutaminase during storage. Acta Period. Technol. 39: 11-19.

Iličić, M. D., S. D. Milanović, M. D. Carić, L. P. Dokić and K. G. Kanurić. 2014. Effect of transglutaminase on texture and flow properties of stirred probiotic yoghurt during storage. J. Texture Stud. 45: 13-19.

ISO. 2012. Sensory analysis. Methodology. Guideliness for Monitoring the Performance of a Quantitative Sensory Panel. International Organization for Standardization, Geneva, Switzerland.

ISO. 2007. Sensory Analysis. General Guidance for the Design of Test Rooms. International Organization for Standardization, Geneva, Switzerland.

Jaros, D., C. Partschefeld, T. Henle and H. Rohm. 2006. Transglutaminase in dairy products: Chemistry, physics, applications. J. Texture. Stud. 37: 113-155.

Kok, C. R. and R. Hutkins. 2018. Yogurt and other fermented foods as sources of health-promoting bacteria. Nutr. Rev. 76: 4-15.

Lee, W. J. and J. A. Lucey. 2006. Impact of gelation conditions and structural breakdown on the physical and sensory properties of stirred yogurts. J. Dairy Sci. 89: 2374-2385.

Lee, W. J. and J. A. Lucey. 2010. Formation and physical properties of yogurt. Asian Austral. J. Anim. Sci. 23: 1127-1136.

Lesme, H., C. Rannou, M. H. Famelar, S. Bouhallab and C. Prost. 2020. Yogurts enriched with milk proteins: Texture properties, aroma release and sensory perception. Trends Food Sci. Technol. 98: 140-149.

Liang, F., L. Li, T. He, X. Zhou, S. Jiang and J. Lu. 2020. Effect of transglutaminase on gel properties of surimi and precocious Chinese mitten crab (Eriocheir sinensis) meat. Food Hydrocoll. 98: 105261

Lorenzen, P. C., H. Neve, A. Mautner and E. Schlimme. 2002. Effect of enzymatic cross-linking of milk proteins on functional properties of set-style yoghurt. Int. J. Dairy Technol. 55: 152-157.

Loveday, S. M., A. Sarkar and H. Singh. 2013. Innovative yoghurts: Novel processing technologies for improving acid milk gel texture. Trends Food Sci. Technol. 33: 5-20.

Lucey, J. A. 2004. Cultured dairy products: An overview of their gelation and texture properties. Int. J. Dairy Technol. 57: 77-84.

Mahmood, W. A. and N. H. Sebo. 2012. Improvement of yogurt properties by microbial transglutaminase. Jordan. J. Agric. Sci. 8: 333-342.

Miwa, N. 2020. Innovation in the food industry using microbial transglutaminase: Keys to success and future prospects. Anal. Biochem. 597: 113638

Mostafa, H. S. 2020. Microbial transglutaminase: An overview of recent applications in food and packaging. Biocatal. Biotransform. 38: 161-177.

Myllärinen, P., J. Buchert and K. Autio. 2007. Effect of transglutaminase on rheological properties and microstructure of chemically acidified sodium caseinate gels. Int. Dairy J. 17: 800-807.

Nguyen, P. T. M., O. Kravchuk, B. Bhandari and S. Prakash. 2017. Effect of different hydrocolloids on texture, rheology, tribology and sensory perception of texture and mouthfeel of low-fat potset yoghurt. Food Hydrocoll. 72: 90-104.

O'Sullivan, M. M., A. L. Kelly and P. F. Fox. 2002. Effect of transglutaminase on the heat stability of milk: A possible mechanism. J. Dairy Sci. 85: 1-7.

Özer, B., H. A. Kirmaci, S. Oztekin, A. Hayaloglu and M. Atamer 2007. Incorporation of microbial transglutaminase into non-fat yogurt production. Int. Dairy J. 17: 199-207.

Pakseresht, S., M. Mazaheri Tehrani and S. M. A. Razavi. 2017. Optimization of low-fat set-type yoghurt: Effect of altered whey protein to casein ratio, fat content and microbial transglutaminase on rheological and sensorial properties. J. Food Sci. Technol. 54: 2351-2360.

Pereira, R., L. Matia-Merino, V. Jones and H. Singh. 2006. Influence of fat on the perceived texture of set acid milk gels: A sensory perspective. Food Hydrocoll. 20: 305-313.

R Core Team. 2019. R: A Language and Environment for Statistical Computing. R Foundation for Statistical Computing, Vienna, Austria.

Romeih, E. and G. Walker. 2017. Recent advances on microbial transglutaminase and dairy application. Trends Food Sci. Technol. 62: 133-140.

Romeih, E. A., M. Abdel-Hamid and A. A. Awad. 2014. The addition of buttermilk powder and transglutaminase improves textura and organoleptic properties of fat-free buffalo yogurt. Dairy Sci. Technol. 94: 297-309.

Şanli, T., E. Sezgi, O. Deveci, E. Şenel and M. Benli. 2011. Effect of using transglutaminase on physical, chemical and sensory properties of set-type yoghurt. Food Hydrocoll. 25: 1477-1481.

Santhi, D., A. Kalaikannan, P. Malairaj and S. A. Prabhu. 2017. Application of microbial transglutaminase in meat foods: A review. Crit. Rev. Food Sci. Nutr. 57: 2071-2076.

Schmidt, R. H., M. M. Vargas, K. L. Smith and J. J. Jezeski. 1985 The effect of ultra-high temperature milk processing on yogurt texture. J. Food Proc. Preserv. 9: 235-240.

Setiadi, S. and J. P. Ramdhani. 2018. Effect of Transglutaminase Addition to Chemical, Physical, and Culture Survivability of Yogurt during Storage Period. E3S Web of Conferences (EDP Sciences), pp. 03042.

Sharma, R., P. C. Lorenzen and K. B. Qvist. 2001. Influence of transglutaminase treatment of skim milk on the formation of $\varepsilon$-(Y-glutamyl) lysine and the susceptibility of individual proteins towards crosslinking. Int. Dairy J. 11: 785-793.

Sidari, R., A. Martorana, C. Zappia, A. Mincione and A. M. Giuffrè 2020. Persistence and effect of a multistrain starter culture on antioxidant and rheological properties of novel wheat sourdoughs and bread. Foods. 9: 1258.

Sidari, R. and R. Tofalo. 2019. A comprehensive overview on microalgal-fortified/based food and beverages. Food Rev. Int. 


\section{5: 778-805.}

Sodini, I., F. Remeuf, C. Haddad and G. Corrieu. 2004. The relative effect of milk base, starter, and process on yogurt texture: A review. Crit. Rev. Food Sci. Nutr. 44: 113-137.

Tamine, A. Y. and R. K. Robinson. 1999. Yoghurt: Science and Technology. Boca Ratón, Florida.

Tamjidi, F., A. Nasirpour and M. Shahedi. 2012. Physicochemical and sensory properties of yogurt enriched with microencapsulated fish oil. Food Sci. Technol. Int. 18: 381-390.

Torrico, D. D., J. Tam, S. Fuentes, C. G. Viejo and F. R. Dunshea. 2020. Consumer rejection threshold, acceptability rates, physicochemical properties, and shelf-life of strawberry-flavored yogurts with reductions of sugar. J. Sci. Food Agric. 100: 3024-3035.

Tsevdou, M. S., Eleftheriou E. G. and P. S. Taoukis. 2013. Transglutaminase treatment of thermally and high pressure processed milk: Effects on the properties and storage stability of set yoghurt. Innov. Food Sci. Emerg. Technol. 17: 144-152.

Vázquez, M. and M. E. Guerra-Rodríguez. 2012. Food Additive Containing Transglutaminase Enzyme Obtained by Fermentation of Culture Media Formulated with Milk, Potato and Glycerol. Spanish Patent No. ES 2376439.
Williams, E. B., B. Hoope, A. Spiro and S. Stanner. 2015. The contribution of yogurt to nutrient intakes across the life course. Nutr. Bull. 40: 9-32.

Xing, G., C. Valeria, L. Giosafatto, A. Carpentieri and R. Pasquino. 2020. Gelling behavior of bio-tofu coagulated by microbial transglutaminase combined with lactic acid bacteria. Food Res. Int. 134: 109200.

Xing, Q., Y. M, X. Fu, Q. Cao, Y. Zhang and C. You. 2020. Effects of heat treatment, homogenization pressure, and overprocessing on the content of furfural compounds in liquid milk. J. Sci. Food Agric. 100: 5276-5282.

Yüksel, Z. and Y. K. Erdem. 2010. The influence of transglutaminase treatment on functional properties of set yoghurt. Int. J. Dairy Technol. 63: 86-97.

Zhang, S., L. Liu, Y. Su, H. Li, Q. Sun, X. Liang and J. Lv. 2011. Antioxidative activity of lactic acid bacteria in yogurt. Afr. J. Microbiol. Res. 5: 5194-5201.

Ziarno, M. and D. Zaręba. 2020. The effect of the addition of microbial transglutaminase before the fermentation process on the quality characteristics of three types of yogurt. Food Sci. Biotechnol. 29: $109-119$ 